\title{
Factors Influencing Acromial and Scapular Spine Strain after Reverse Total Shoulder Arthroplasty: A Systematic Review of Biomechanical Studies
}

\author{
Alexander Paszicsnyek ${ }^{1} \oplus$, Olivia Jo ${ }^{2}$, Harshi Sandeepa Rupasinghe ${ }^{3}$, David C. Ackland ${ }^{3}$, Thomas Treseder ${ }^{2}$, \\ Christopher Pullen ${ }^{2}{ }^{-0}$, Greg Hoy ${ }^{4}$, Eugene T. Ek ${ }^{4}\left(\mathbb{D}\right.$ and Lukas Ernstbrunner ${ }^{2,3,4, *}$
}

check for

updates

Citation: Paszicsnyek, A.; Jo, O.; Rupasinghe, H.S.; Ackland, D.C.; Treseder, T.; Pullen, C.; Hoy, G.; Ek, E.T.; Ernstbrunner, L. Factors Influencing Acromial and Scapular Spine Strain after Reverse Total Shoulder Arthroplasty: A Systematic Review of Biomechanical Studies. J. Clin. Med. 2022, 11,361. https:// doi.org/10.3390/jcm11020361

Academic Editor: Luc Favard

Received: 16 November 2021

Accepted: 7 January 2022

Published: 12 January 2022

Publisher's Note: MDPI stays neutral with regard to jurisdictional claims in published maps and institutional affiliations.

Copyright: (C) 2022 by the authors. Licensee MDPI, Basel, Switzerland. This article is an open access article distributed under the terms and conditions of the Creative Commons Attribution (CC BY) license (https:// creativecommons.org/licenses/by/ $4.0 /)$.
1 Department of Orthopaedics and Traumatology, Paracelsus Medical University, Strubergasse 21, 5020 Salzburg, Austria; ap@ortho-unfall.at

2 Department of Orthopaedic Surgery, Royal Melbourne Hospital, 300 Grattan Street, Parkville, Melbourne, VIC 3050, Australia; jo.olivia1310@gmail.com (O.J.); tomtreseder@me.com (T.T.); cmpullen@bigpond.com (C.P.)

3 Department of Biomedical Engineering, University of Melbourne, Parkville, Melbourne, VIC 3010, Australia; rupasingheh@student.unimelb.edu.au (H.S.R.); dackland@unimelb.edu.au (D.C.A.)

4 Melbourne Orthopaedic Group, Windsor, VIC 3181, Australia; gahoy@mog.com.au (G.H.); eugene_ek@me.com (E.T.E.)

* Correspondence: lukas.ernstbrunner@icloud.com

\begin{abstract}
Background: Acromial and scapular spine fractures after reverse total shoulder arthroplasty (RTSA) can be devastating complications leading to substantial functional impairments. The purpose of this study was to review factors associated with increased acromial and scapular spine strain after RTSA from a biomechanical standpoint. Methods: A systematic review of the literature was conducted based on PRISMA guidelines. PubMed, Embase, OVID Medline, and CENTRAL databases were searched and strict inclusion and exclusion criteria were applied. Each article was assessed using the modified Downs and Black checklist to appraise the quality of included studies. Study selection, extraction of data, and assessment of methodological quality were carried out independently by two of the authors. Only biomechanical studies were considered. Results: Six biomechanical studies evaluated factors associated with increased acromial and scapular spine strain and stress. Significant increases in acromial and scapular spine strain were found with increasing lateralization of the glenosphere in four of the included studies. In two studies, glenosphere inferiorization consistently reduced acromial strain. The results concerning humeral lateralization were variable between four studies. Humeral component neck-shaft angle had no significant effect on acromial strain as analysed in one study. One study showed that scapular spine strain was significantly increased with a more posteriorly oriented acromion $\left(55^{\circ}\right.$ vs. $\left.43^{\circ} ; p<0.001\right)$. Another study showed that the transection of the coracoacromial ligament increased scapular spine strain in all abduction angles $(p<0.05)$. Conclusions: Glenoid lateralization was consistently associated with increased acromial and scapular spine strain, whereas inferiorization of the glenosphere reduced strain in the biomechanical studies analysed in this systematic review. Humeral-sided lateralization may increase or decrease acromial or scapular spine strain. Independent of different design parameters, the transection of the coracoacromial ligament resulted in significantly increased strains and scapular spine strains were also increased when the acromion was more posteriorly oriented. The results found in this systematic review of biomechanical in-silico and in-vitro studies may help in the surgical planning of RTSA to mitigate complications associated with acromion and scapular spine fracture.
\end{abstract}

Keywords: reverse total shoulder arthroplasty; acromion fracture; scapular spine fracture; design parameters; biomechanics 


\section{Introduction}

The indications for reverse total shoulder arthroplasty (RTSA) are broad and include irreparable rotator cuff tear or arthropathy [1-6], complex proximal humerus fractures in elderly patients [7-10], and revision arthroplasty [11]. RTSA is designed to medialize the glenohumeral joint center of rotation through offset lateralisation and inferiorization of the humerus, thereby increasing the deltoid moment arm. This in turn decreases the required deltoid force to combat gravity during abduction [12]. However, the inherent change in upper limb biomechanics, whilst offering advantages such as increased abduction and stability [13], results in increased stresses on the acromion and scapular spine [14]. Acromial and/or scapular spine fractures are relatively common complications of RTSA, occurring in up to $10 \%$ of patients [15-22]. These fractures have been associated with a substantial decline in outcomes with a reduced range of motion [22,23] and increased pain [24]. The management of these fractures, particularly Levy zone II and III fractures $[15,20,25,26]$ is challenging [20,24,27] and associated with high rates of malunion or non-union $[16,17,20,22]$. As a result, there has been increasing interest in preventing these fractures from occurring in the first place $[16,17,20,22]$.

Patient factors such as female gender, osteoporosis, or acromial anatomy have been identified as risk factors for acromial and scapular spine fractures after RTSA [28-30]. Implant factors, such as increased lateralization of the glenoid component, were proposed to play a significant role in increasing stress on the acromion [31,32]. It has also been suggested that combined medialization and proximalisation of the glenoid component, and hence the joint center of rotation, is associated with acromial fractures [33]. While lowering of the humerus is thought to increase acromial stress through excessive tensioning of the deltoid $[27,34]$, humeral lateralization may have a protective effect against fracture [33]. The exact biomechanics of acromial and scapular spine strain patterns remain poorly understood.

The purpose of this systematic review was therefore to analyse the biomechanical impact of different RTSA design features on acromion and scapular spine strain after RTSA and to identify potential implant- and anatomy-related risk factors for acromial and scapular spine fractures in RTSA.

\section{Material and Methods}

\subsection{Search Strategy}

The systematic review followed the Preferred Reporting Items of Systematic Reviews and Meta-analysis (PRISMA) guidelines (Supplementary Material, File S1) [35], and was registered in the International Prospective Register for Systematic Reviews and Metaanalysis (PROSPERO): CRD42021297115 (Supplementary Material, File S2). A systematic search was conducted of PubMed, Embase, OVID Medline, and CENTRAL (Cochrane Central Register of Controlled trials) databases. The following keywords were used for the search: "reverse shoulder arthroplasty", "reverse total shoulder prosthesis", "reverse shoulder prosthesis" were combined with "acromial fracture", "acromial strain", " acromial pathology", "acromial stress", as well as "scapular spine fracture", "scapular spine strain", "scapular spine pathology", and "scapular spine stress" (Supplementary Material, File S3).

\subsection{Selection Process}

Two authors (A.P., O.J.) independently screened titles, abstracts, and full texts using the predefined inclusion and exclusion criteria. In cases of discrepancy, the senior author (L.E.) was consulted until a final consensus was reached. Biomechanical studies reporting acromial and scapular spine strains or stress after RTSA were chosen based on the following inclusion criteria:

(1) Biomechanical in-vitro or in-silico studies;

(2) Studies reporting on acromion or scapular spine fracture, strain, and stress;

(3) Studies in the German or English language;

(4) Studies released between January 2015 and May 2021. 
We excluded editorial comments, review articles, conference proceedings, outcome studies, and studies that were not in the English or German language.

\subsection{Data Interpretation}

Basic study designs, number of specimen, type of study, and measuring locations were collected, as well as all aspects of implant design and acromial and scapula anatomy that may influence acromial and/or scapular strain after RTSA. Factors defined for this analysis included glenoid-sided and humeral-sided offset, deltoid lengthening, glenosphere inferiorization, neck-shaft angle (NSA), acromial morphology, and coracoacromial ligament integrity. A total of $25 \mathrm{~mm}$ of deltoid lengthening was used as a threshold value as it was associated with a decline in shoulder function in a previous study [36]. Stress and strain values obtained by the biomechanical studies were recorded. Stress is defined as the ratio of the force to the cross-sectional area and strain is defined as the relative deformation of a material when a given force is applied [37]. Information on the stress by location was also extracted based on the Levy classification for acromial stress fractures [20]. Type I involves a fracture through the midpart of the acromion caused by the anterior and middle deltoid origin. Type II was defined as a fracture caused by the entire middle deltoid segment and portion of posterior deltoid origin. Type III fractures involve the entire middle and posterior deltoid origin (Figure 1).

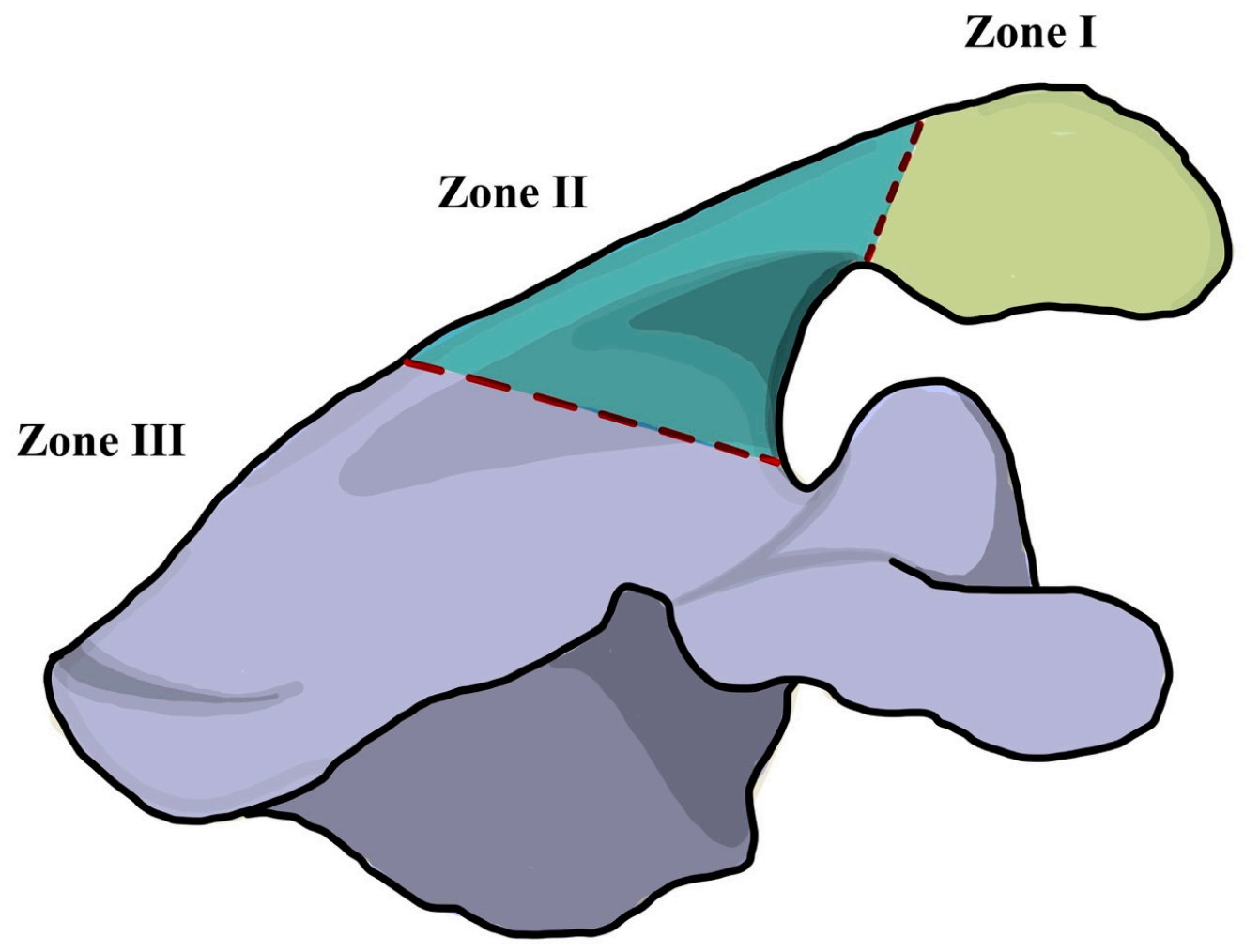

Figure 1. Illustration of the Levy classification for acromial stress fractures after reverse total shoulder arthroplasty [20]. Zone I involves a fracture through the midpart of the acromion caused by the anterior and middle deltoid origin. Zone II was defined as a fracture caused by the entire middle deltoid segment and portion of posterior deltoid origin. Zone III fractures involve the entire middle and posterior deltoid origin.

\subsection{Study Quality Assessment}

A risk of bias assessment was conducted using a modified Downs and Black checklist [38]. This checklist is a quality assessment tool used for systematic reviews of biomechanical studies [39]. With a maximum possible score of 12 , the methodological quality of the included studies was classified into high ( $>9$ points), moderate (6-8 points), and low ( $<5$ points). Two reviewers (A.P. and O.J.) assessed studies independently. In case of 
inter-rater disagreement, the senior author (L.E.) was consulted until a final consensus was reached.

\section{Results}

\subsection{Search Results}

Using combinations of the predefined search terms, a total of 1386 studies were identified. A total of 171 studies remained after the removal of duplicates and screening of titles. After abstract screening, 12 studies underwent full-text evaluation. Three studies were excluded as full-text articles were not available [40-42]. Two studies did not report on scapular strain or stress [43,44], and one study was a systematic review [45]. Six studies $[14,29,30,46-48]$ met the inclusion and exclusion criteria and were included in this study (Figure 2).

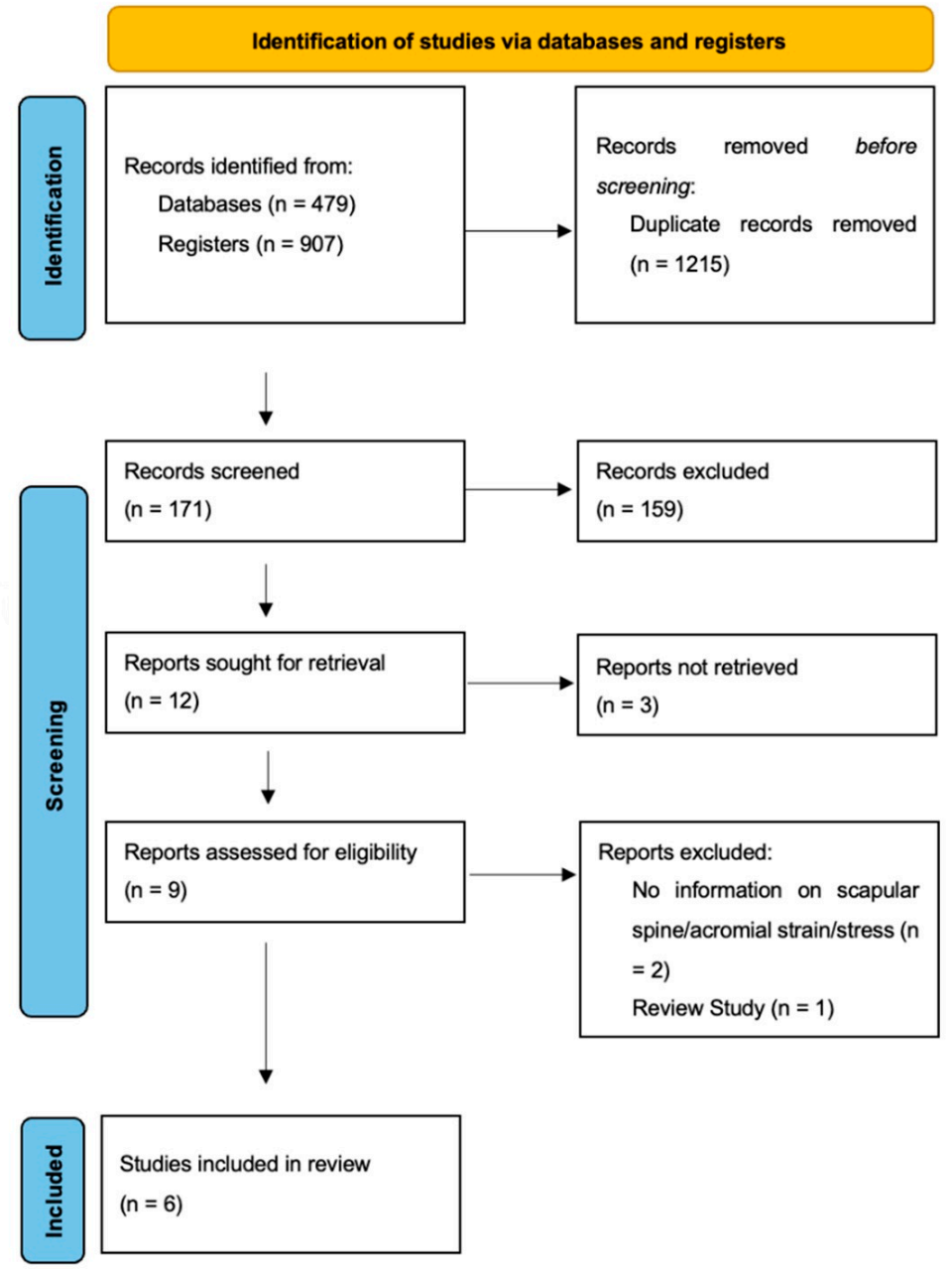

Figure 2. PRISMA flow diagram of the systematic search.

\subsection{Study Quality Assessment}

In this review, 5 studies $[14,29,30,46,47]$ were of high methodological quality and one study [48] was of moderate quality due to the limited number of specimens included $(n=1)$ and lack of appropriate statistical analysis.

\subsection{Study Characteristics}

Three of the included studies were in-silico studies consisting of computational analyses, with all of them using finite element (FE) modelling [14,48,49] (Figure 3). 

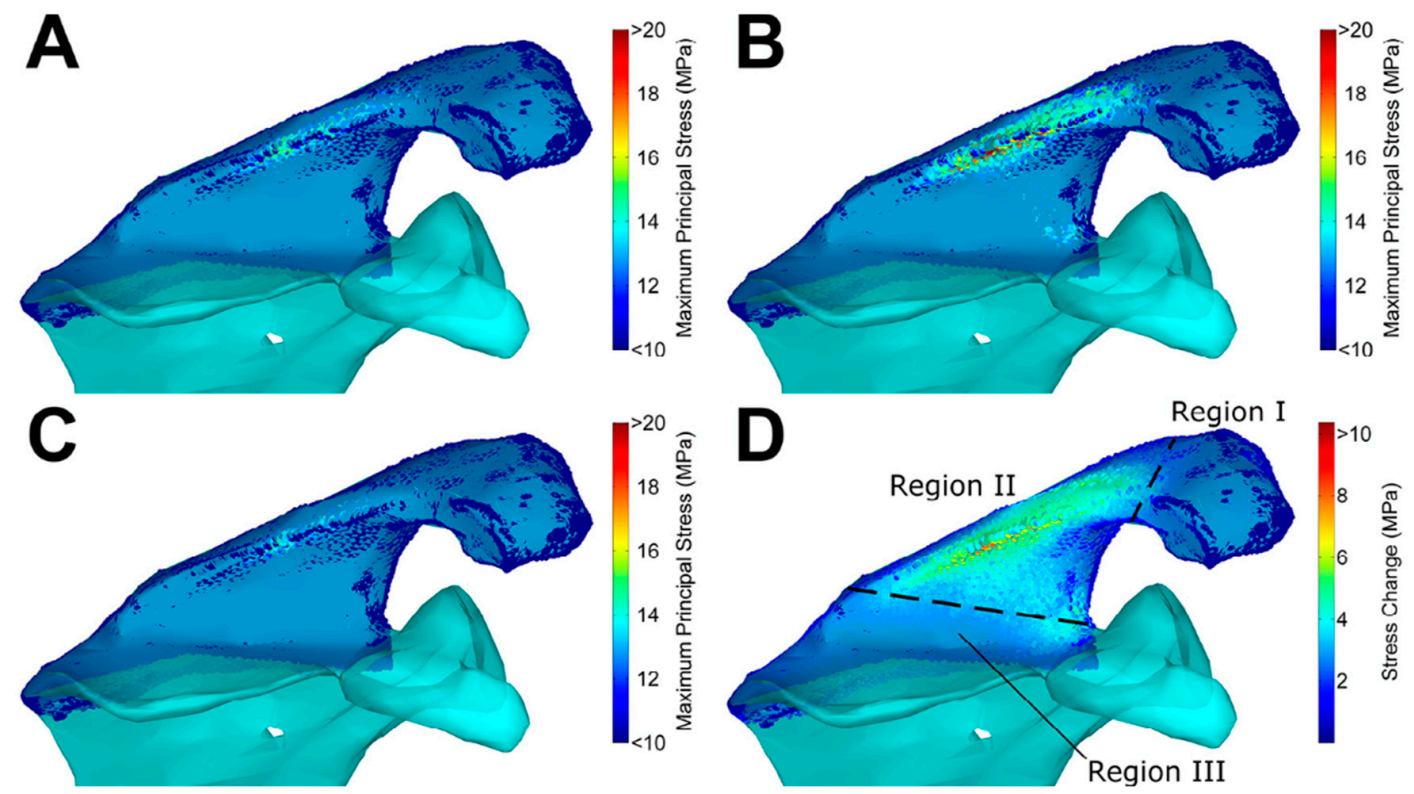

Figure 3. Finite element analysis on the influence of implant positioning in reverse total shoulder arthroplasty on acromial and scapular spine stresses by Wong et al. [47]. Reprinted with permission from ref. [47]. Copyright 2016 Elsevier. (A) Baseline implant configuration, (B) maximum stress configuration, (C) minimum stress configuration, and (D) stress increase from minimum to maximum stress configuration. Regions are as defined by Levy et al. [20].

The other 3 in-vitro studies used cadaveric models in combination with a shoulder simulator in different shoulder positions $[29,30,46]$ (Figure 4).
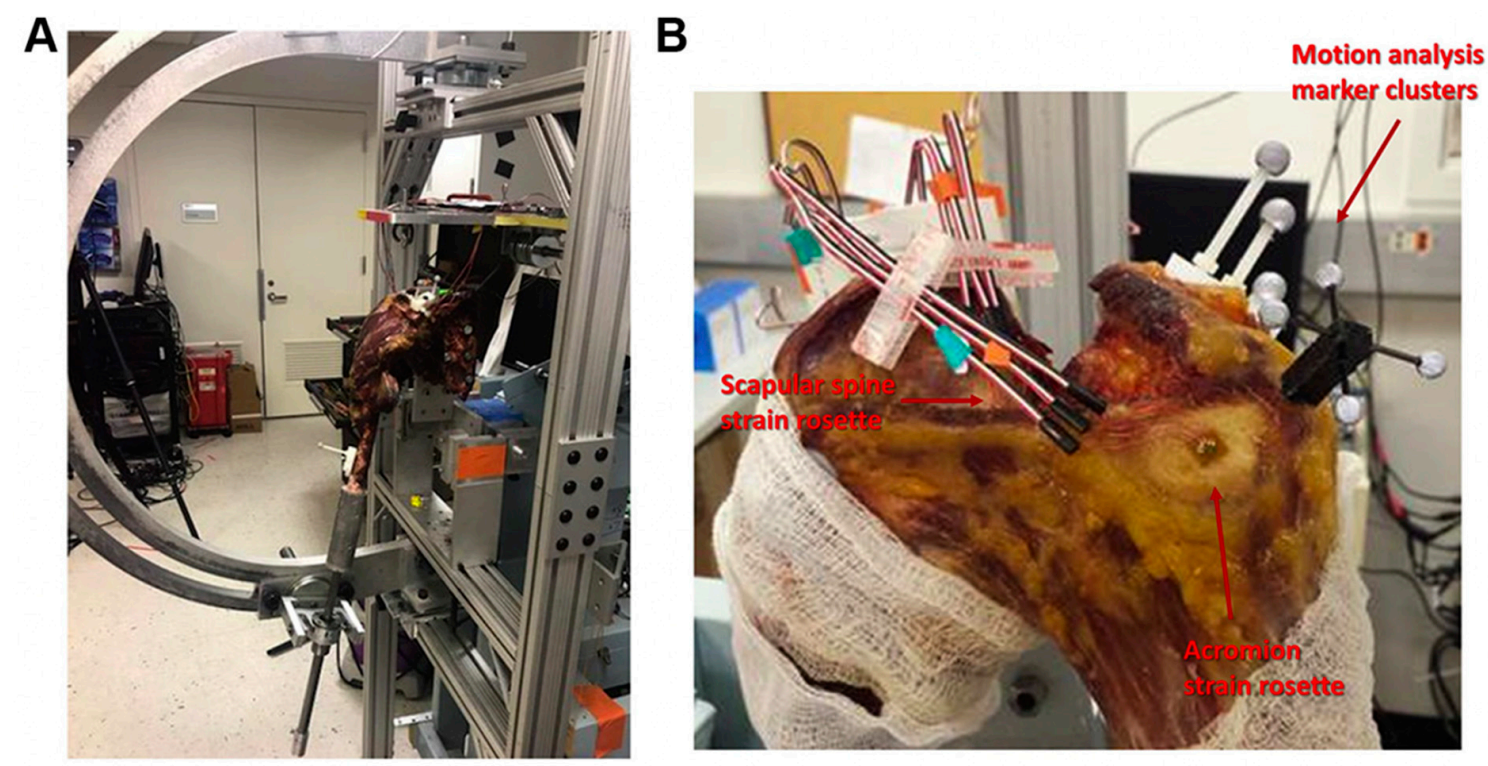

Figure 4. Biomechanical set up of the study by Shah et al. [29]. Reprinted with permission from ref. [29]. Copyright 2020 Elsevier. Biomechanical testing apparatus. (A) The humerus was mounted to a 6-degree-of-freedom shoulder simulator that can simulate different levels of abduction. (B) Strain rosettes (Vishay Measurements Group), 3 strain gauges overlapping and patterned in a 90 angle, were rigidly glued on to the surface of the acromial body and the scapular spine to represent the locations of Levy et al. [20] type II and type III fractures, respectively.

A total of 46 cadavers were used in the included studies. Five studies $[14,29,30,46,48]$ measured strain/stress according to the Levy zones [20] (Table 1). 
Table 1. Characteristics of the included studies.

\begin{tabular}{|c|c|c|c|c|c|c|c|c|}
\hline Study & $\begin{array}{c}\text { Specimen Type, } \\
\text { Number, Age (Range) }\end{array}$ & Study Type & Implant Used & $\operatorname{NSA}\left({ }^{\circ}\right)$ & Humeral Offset (mm) * & $\begin{array}{l}\text { Glenosphere } \\
\text { Offset }(\mathrm{mm}) \text { * }\end{array}$ & Outcome(s) Assessed & $\begin{array}{c}\text { Scapular } \\
\text { Strain/Stress } \\
\text { Location }^{+} \\
\end{array}$ \\
\hline $\begin{array}{l}\text { Kerrigan (2021) [46], } \\
\text { Canada, } \\
\text { DCOI }\end{array}$ & Cadaveric, 8, 73 (61-88) & $\begin{array}{l}\text { In-vitro biomechanical } \\
\text { study (quasi-static) }\end{array}$ & $\begin{array}{l}\text { Custom modular } \\
42 \mathrm{~mm} \text { glenosphere } \\
\text { Onlay humeral tray. } \\
\text { No further } \\
\text { specifications }\end{array}$ & $135,145,155$ & $-5.0,+5.0,+15.0$ & $\begin{array}{l}\text { Lateralization: } \\
\quad+5.0\end{array}$ & $\begin{array}{c}\text { Scapular strain during: } \\
\text { A: Abduction }\left(0-90^{\circ}\right) \text { in scapular } \\
\text { plane and forward elevation }\left(0-90^{\circ}\right) \text {; } \\
\text { B: Humeral lateralization; } \\
\text { C: Varying neck shaft angles }\end{array}$ & $\begin{array}{l}\text { Levy region I, II, } \\
\text { and III }\end{array}$ \\
\hline $\begin{array}{l}\text { Lockhart (2020) [14], } \\
\text { Canada }\end{array}$ & $\begin{array}{c}\text { CT images of cadaveric } \\
\text { shoulders, } 10,68 \\
(49-87)\end{array}$ & $\begin{array}{c}\text { In-silico } \\
\text { finite element } \\
\text { modelling (quasi-static) }\end{array}$ & $\begin{array}{l}38 \mathrm{~mm} \text { glenosphere } \\
\text { Onlay humeral tray. } \\
\text { No further } \\
\text { specifications }\end{array}$ & 155 & $+15.0,+20.0,+25.0$ & $\begin{array}{c}\text { Inferiorization: } 0, \\
2.5,5.0 \\
\text { Lateralization: } \\
0,+5.0,+10.0\end{array}$ & $\begin{array}{c}\text { Acromial stress during: } \\
\text { A: Abduction }\left(0^{\circ}\right) \text {, scapular plane } \\
\text { elevation }\left(30^{\circ}\right) \text {, forward } \\
\text { elevation }\left(60^{\circ}\right) \\
\text { B: Loading }(0,2.5,5 \mathrm{~kg}) \\
\text { C: Glenosphere lateralization } \\
\text { D: Glenosphere inferiorization } \\
\text { E: Humeral medialization } \\
\text { and lateralization }\end{array}$ & $\begin{array}{l}\text { Levy region I, II, } \\
\text { and III }\end{array}$ \\
\hline $\begin{array}{c}\text { Shah (2020) [29], } \\
\text { USA }\end{array}$ & $\begin{array}{c}\text { Cadaveric, } 10,53.2 \\
(37-63)\end{array}$ & $\begin{array}{l}\text { In-vitro biomechanical } \\
\text { study (quasi-static) }\end{array}$ & $\begin{array}{l}\text { Zimmer Biomet } \\
\text { Comprehensive } \\
36 \text { mm glenosphere. } \\
\text { Onlay humeral tray }\end{array}$ & 147 & $\begin{array}{c}+3.0,+5.0,+8.0,+10.0 \\
+13.0\end{array}$ & $\begin{array}{l}\text { Lateralization: } \\
\quad 0,+6.0\end{array}$ & $\begin{array}{l}\text { Acromial and scapular strain and } \\
\text { deltoid lengthening: } \\
\text { A: Based on anatomical orientation } \\
\text { of acromion } \\
\text { B: During glenosphere lateralization } \\
\text { C: During humeral lateralization }\end{array}$ & $\begin{array}{l}\text { Levy region II } \\
\text { and III }\end{array}$ \\
\hline $\begin{array}{c}\text { Taylor (2020) [30], } \\
\text { USA }\end{array}$ & $\begin{array}{c}\text { Cadaveric, } 8,68 \\
(56.9-79.1)\end{array}$ & $\begin{array}{l}\text { In-vitro biomechanical } \\
\text { study (dynamic) }\end{array}$ & $\begin{array}{l}\text { Zimmer Biomet } \\
\text { Comprehensive } \\
36 \mathrm{~mm} \text { glenosphere. } \\
\text { Onlay humeral tray }\end{array}$ & 147 & +3.0 & $\begin{array}{l}\text { No change } \\
\text { in offset }\end{array}$ & $\begin{array}{l}\text { Maximal principal strains on the } \\
\text { acromion and scapular strain when: } \\
\text { A: Coracoacromial ligament intact } \\
\text { B: Coracoacromial } \\
\text { ligament transacted }\end{array}$ & $\begin{array}{l}\text { Levy region II } \\
\text { and III }\end{array}$ \\
\hline $\begin{array}{l}\text { Wong (2016) [47], } \\
\text { Canada, } \\
\text { DCOI }\end{array}$ & $\begin{array}{c}\text { Cadaveric, } 10,68 \\
(49-87)\end{array}$ & $\begin{array}{l}\text { In-silico finite element } \\
\text { modelling (dynamic) }\end{array}$ & $\begin{array}{c}\text { Delta Xtend, } \\
\text { Depuy Synthes } \\
38 \text { mm glenosphere. } \\
\text { Onlay humeral tray }\end{array}$ & 155 & $-5.0,0,+5.0$ & $\begin{array}{c}\text { Inferiorization:0, } \\
2.5,5.0 \\
\text { Lateralization: } \\
0,+5.0,+10.0\end{array}$ & $\begin{array}{l}\text { Acromial stress during: } \\
\text { A: Abduction }\left(0-120^{\circ}\right) \\
\text { B: Glenosphere inferiorization } \\
\text { C: Glenosphere lateralization } \\
\text { D: Humeral medialization } \\
\text { and lateralization }\end{array}$ & \\
\hline $\begin{array}{c}\text { Zeng (2021) [48], } \\
\text { USA }\end{array}$ & $\begin{array}{l}\mathrm{CT} \text { images of } \\
\text { representative female } \\
\text { subject, } 1\end{array}$ & $\begin{array}{l}\text { In-silico finite element } \\
\text { modelling (dynamic) }\end{array}$ & $\begin{array}{l}\text { Zimmer Anatomical } \\
\text { Reverse } 36 \mathrm{~mm} \\
\text { glenosphere. } \\
\text { Onlay humeral tray }\end{array}$ & - & - & $\begin{array}{l}\text { Lateralization: } \\
0,+6.0,+12.0\end{array}$ & $\begin{array}{l}\text { A: Maximal principal strain, stress } \\
\text { and von Milses stress on scapula } \\
\text { during glenosphere lateralization } \\
\text { B: Deltoid muscle forces during } \\
\text { glenosphere lateralization }\end{array}$ & $\begin{array}{l}\text { Levy region I, II, } \\
\text { and III }\end{array}$ \\
\hline
\end{tabular}

NSA, neck-shaft angle; DCOI, declared conflict of interest; * Positive values indicate lateralization and negative values indicate medialization of the component; ${ }^{\dagger}$ Acromial and scapular spine stress and strain regions were classified according to the Levy classification [20]. 


\subsection{Glenoid Lateralization}

Four studies of high to moderate qualities reported on the influence of glenoid component lateralization on acromial and scapular spine strain $[14,29,47,48]$, and showed a consistent increase in acromial and scapular spine stress and strain with glenoid lateralization (Figure 5).

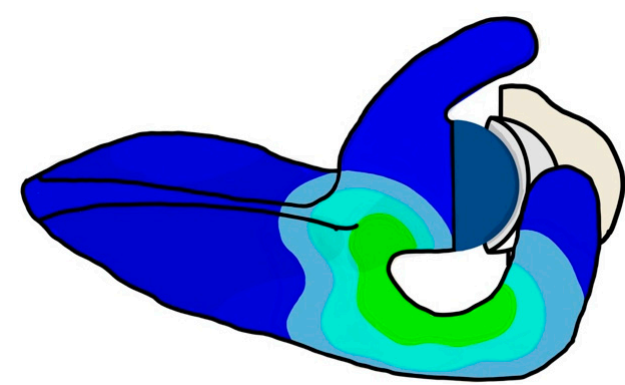

(A)

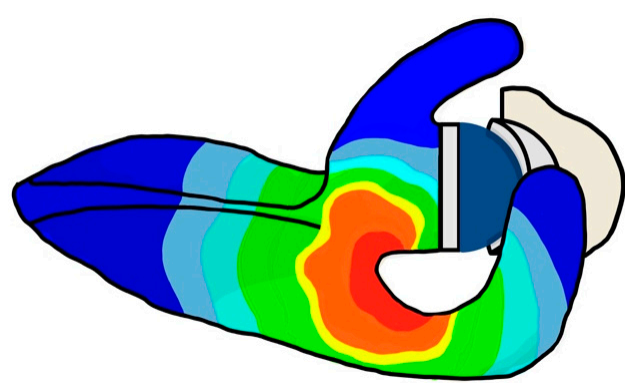

(B)

Figure 5. Illustration of the influence of glenoid component lateralization on acromial and scapular spine strain. Acromial and scapular spine strain are increased when comparing a (A) non-lateralized glenoid component with a (B) lateralized glenoid component.

Lockhart et al. [14] showed in their computational study that the lateralization of the glenoid component by $10 \mathrm{~mm}$ increased the maximum stress on the acromion during abduction by $9.0 \mathrm{MPa}$ compared to the unlateralized condition $(16 \%, p<0.001)$. During forward elevation, maximum acromial stress increased by $4.0 \mathrm{MPa}(11 \%, p=0.009)$ at $5-\mathrm{mm}$ lateralization and by $8.0 \mathrm{MPa}(21 \%, p<0.001)$ at $10-\mathrm{mm}$ lateralization. In an in-silico study by Wong et al. [47], the authors reported a significant increase of $4.1 \mathrm{MPa}(17 \%, p=0.003)$ in acromial stress during abduction with a glenosphere lateralized by $10 \mathrm{~mm}$ compared to the 0-mm lateralization condition. Furthermore, Zeng et al. [48] showed that $12 \mathrm{~mm}$ of glenosphere lateralization increased deltoid force by $16 \%$ and peak acromial stress by 11.6 MPa compared to 0-mm lateralization in their computational analyses. Shah et al. [29] demonstrated that in all humeral onlay conditions, lateralization of the glenosphere increased acromial and scapular spine strains in their cadaveric study. A 6-mm increase in glenosphere lateralization with a +10 -mm lateralized humeral onlay tray resulted in a significant increase in acromial strain when compared to $0 \mathrm{~mm}$ of lateralization $(905 \mu \varepsilon$ vs. $962 \mu \varepsilon$; $6 \%, p=0.029$ ). Similarly, with a $+13-\mathrm{mm}$ lateralized humeral onlay, acromial strain increased from $962 \mu \varepsilon$ to $1112 \mu \varepsilon(14 \%, p=0.048)$ when the glenosphere was lateralized by $6 \mathrm{~mm}$.

\subsection{Glenoid Inferiorization}

The effect of inferiorization of the glenosphere on acromial stress was assessed in 2 in-silico studies of high quality [14,47]. Lockhart et al. [14] found a significant reduction in peak acromion stress during abduction with $2.5-\mathrm{mm}$ glenosphere inferiorization by $1.8 \mathrm{MPa}(3 \%, p=0.001)$, while 5 -mm inferiorization resulted in a greater decrease by $3 \mathrm{Mpa}$ $(5 \%, p=0.002)$ in acromial stress when compared with $0 \mathrm{~mm}$ of inferiorization. Significant reduction in acromial stress was also observed in the sagittal plane by $2 \mathrm{MPa}(5 \%, p=0.041)$ for $5 \mathrm{~mm}$ of inferiorization. Wong et al. [47] found a reduction of acromial stress during abduction by $0.4 \mathrm{MPa}(2 \%, p=0.008)$ with $2.5 \mathrm{~mm}$ of inferiorization, while a decrease by $0.7 \mathrm{MPa}(3 \%, p=0.024)$ was noted with $5 \mathrm{~mm}$ of inferiorization.

\subsection{Humeral Lateralization}

Four studies of high quality reported the effect of lateralization of the humerus on acromial stress during glenohumeral abduction $[14,29,46,47]$. In the cadaveric study by Shah et al. [29], incremental increase of humeral onlay $(+3,+5,+8,+10,+13 \mathrm{~mm})$ resulted in significantly increased maximum strains on the acromion (i.e., $348 \mu \varepsilon$ vs. $427 \mu \varepsilon$ vs. $609 \mu \varepsilon$ vs. $696 \mu \varepsilon$ vs. $962 \mu \varepsilon$, respectively; $p<0.05$ ). Similarly, Wong et al. [47] showed that during 
abduction, lateralization of the humerus increased acromial stresses by $1.7 \%(0.8 \mathrm{MPa}$; $p=0.051)$, whereas medialization by $5 \mathrm{~mm}$ decreased stresses by $1.4 \%(0.4 \mathrm{MPa} ; p=0.038)$. On the other hand, Kerrigan et al. [46] reported a decrease of strain on the acromion of $34 \%$ with increased lateralization in their in-vitro study $(-5 \mathrm{~mm}$ medialization vs. $15 \mathrm{~mm}$ lateralization; $p=0.042$ ). Lastly, Lockhart et al. [14] reported that humeral offset had no significant effect on acromial strain regardless of the direction of offset (medial or lateral) nor the plane of elevation (abduction or forward elevation).

\subsection{Deltoid Lengthening}

The influence of deltoid lengthening was evaluated in the in-vitro study by Shah et al. [29]. They showed that deltoid length was increased by $16 \mathrm{~mm}$ with the standard onlay humeral insert and standard glenosphere compared to that in the native shoulder. Deltoid length significantly increased to $29 \mathrm{~mm}$ with the $+13 \mathrm{~mm}$ humeral onlay insert $(p<0.01)$. The peak deltoid lengthening of $31 \mathrm{~mm}$ was observed with a $+6-\mathrm{mm}$ lateralized glenosphere combined with a $+13-\mathrm{mm}$ humeral insert. This maximal deltoid lengthening was associated with an acromial strain of $1112 \mu \varepsilon$, which was an increase of $83 \%$ in strain compared to that at $25 \mathrm{~mm}$ of deltoid lengthening $(p=0.012)$. At all other configuration of implants resulting in deltoid lengthening beyond $25 \mathrm{~mm}$, a $79-\mu \varepsilon$ incremental increase in acromial stress per mm lengthening was observed.

\subsection{Neck-Shaft Angle}

The influence of NSA was only reported in one study [46], and did not result in a statistically significant effect $(p>0.05)$ on acromial or scapular stress when the NSA was changed between $135^{\circ}, 145^{\circ}$, and $155^{\circ}$.

\subsection{Acromial Morphology}

Shah et al. reported on the influence of acromial morphology on scapular spine and acromial strains [29]. Of the 10 cadaveric shoulders tested, five shoulders (group A) had higher strain on the scapular spine than on the acromion (1445 $\mu \varepsilon$ vs. $862 \mu \varepsilon$; $p=0.02$ ) at maximal deltoid lengthening. Meanwhile, the remaining five shoulders (group

B) showed higher strain on the acromion than on the scapular spine (1203 $\mu \varepsilon$ vs. $603 \mu \varepsilon$; $p=0.003$ ) at the same degree of deltoid lengthening. They found that group A, with higher scapular spine strain than acromial strain, had a larger mean SSA (i.e., flatter scapular spine), compared to group B, with higher acromial strain than scapular strain $\left(55^{\circ}\right.$ vs. $43^{\circ}$; $p<0.001$ ). Furthermore, group A (higher strain on scapular spine) was found to have a more posteriorly oriented acromion than group B (higher strain on acromion), which had an acromion that was placed more anteriorly $(-5.3 \mathrm{~mm}$ vs. $6.7 \mathrm{~mm}, p<0.001)$.

\subsection{Coracoacromial Ligament}

One in-vitro study [30] reported the influence of the coracoacromial ligament on acromial and scapular spine strain after RTSA in a cadaveric model. Following coracoacromial ligament transection, scapular spine strain at all abduction angles was significantly increased compared with that in the intact condition $(p<0.05)$. The peak scapular spine strain increased by $19.7 \%$ following coracoacromial transection $(1.216 \mu \varepsilon ; p=0.011)$.

\section{Discussion}

The effects of humeral and glenoid lateralization of a non-Grammont design are to bring the lesser and greater tuberosities to a more anatomic position than with the traditional medialized design and to facilitate two important aspects [50]: (1) Increased resting tension of the remaining rotator cuff and deltoid, thus increasing compressive forces on the joint and thus increasing joint stability [31,32,51,52]; and (2) increased wrapping of the deltoid, thus increasing the horizontal stability through compressive force [53,54]. Besides these improved biomechanics of modern RTSA, changing the glenoid offset can have adverse effects, such as reducing the moment arm of the deltoid muscle as well as 
creating large bending moments at the base-plate fixation, which may create an environment where fixation failure is more likely [55].

One of the main findings of this study was that glenoid lateralization significantly and consistently increased acromial and scapular spine stress and strain. As lateralization of the center of rotation reduces the moment arm of the deltoid muscle, increased deltoid forces for abduction are necessary [31,32]. This leads to an increased acromion and scapular spine strain [13,32]. Glenoid lateralization can improve clinical and radiographic outcomes, but it can also be associated with increased acromial and scapular spine strain, and should therefore be considered as a risk factor of acromion and scapular spine fractures, following RTSA.

Inferiorization of the glenosphere uniformly reduced acromial stress across the included studies. This is likely due to the lengthening of the deltoid and a shift in the center of rotation towards a larger deltoid moment arm for abduction. An increased moment arm reduces deltoid forces, thereby reducing forces directly applied to the acromion [14]. In a cadaveric model including 8 shoulders, RTSA with a $2.5-\mathrm{mm}$ glenosphere inferiorization compared to a 4-mm lateralized glenosphere resulted in a reduction in deltoid force to abduct the arm [56]. Therefore, glenosphere inferiorization in combination with glenosphere lateralization (if desired) may neutralize acromion and scapular spine strain, although glenoid lateralization seems to have a larger effect on acromial stress than inferiorization [49].

Lateralization of the humerus has shown variable effects on acromial and/or scapular spine strains. Wong et al. [49] showed in a computational study that, during abduction, lateralization of the humerus increased acromial stress, whereas medialization of the humerus results in significantly decreased acromial stress. The authors believe that this was due to the decreased passive stretch and tensioning of the deltoid with humeral medialization. Shah et al. [29] incrementally increased humeral lateralization and found that onlay system lateralization results in significant deltoid lengthening. This results in a subsequent increase in passive tension in the deltoid and the overall force acting on the acromion and scapular spine, which therefore, increases strain. On the other hand, Kerrigan et al. [46] reported that humeral lateralization caused significant decreases in scapular spine strain during abduction. They hypothesized that increasing humeral lateralization results in a larger moment arm for the deltoid in abduction, which decreased the deltoid force necessary to abduct, which reduces acromial and scapular strain. Accordingly, Giles et al. [31] further demonstrated in a cadaveric model that humeral lateralization decreased the deltoid force required for active abduction due to the increased muscle moment arm. Based on these results, humeral lateralization results in two effects that interplay: (1) It increases the passive tension of the deltoid, resulting in increased force acting on the acromion and scapular spine and (2) it increases the muscle moment arm and therefore decreases the active force necessary for active abduction. The more dominant effect may depend on a number of factors, including implant design. Furthermore, because all the involved studies have used onlay humeral trays, there may be some differences in effects on an inlay model.

The effect of changing NSA on the shoulder range of motion and scapular notching has been studied extensively [57-62]. Implants with more anatomical or varus humeral angles produce increased adduction and external rotation [60], and are less prone to scapular impingement [57]. The impact of the humeral neck-shaft angle on scapular spine strain is less clear and was assessed in one of the included studies [46]. It was found that varying NSA did not influence scapular spine strain in any of the four planes of elevation. This may be because humeral inclination has little [60] or no effect [46] on humeral offset. Thus, more varus humeral component NSA may offer the advantage of reduced scapular notching whilst having minimal impact on scapular spine strain.

Acromial morphology has been shown to influence the distribution of strain on the acromion as well as the scapular spine. Shah. et al. [29] described the influence of acromial and scapular spine orientation in the parasagittal plane on strain patterns. A flatter scapular spine in combination with a more posteriorly oriented acromion resulted in a significantly 
higher strain burden on the scapular spine in comparison to the acromion. Conversely, a more vertically oriented scapular spine in combination with a more anteriorly oriented acromion resulted in a significantly higher strain on the acromion than on the scapular spine. The exact mechanism by which anatomical changes in the scapula influence acromial and scapular spine strain is unclear. Furthermore, another (unknown) factor to consider in order to predict strain tendencies during preoperative planning of RTSA is the influence of thoracic kyphosis [63].

The coracoacromial ligament plays a role in transmitting forces acting on the acromion to the coracoid process and vice versa [64,65]. Taylor et al. [30] showed in a cadaveric study that transecting the coracoacromial ligament results in significantly increased scapular spine strain at all abduction angles. The authors suggest that the coracoacromial ligament alters strain patterns along the acromion and scapular spine. This is a result of the counterbalance role of the coracoacromial ligament. The deltoid creates a cantilever as a result of the shape of the acromion, resulting in the bending of the acromion and therefore raising the strain affecting the scapular spine. This is normally counteracted by the coracoacromial ligament and therefore transection results in an alteration of strain patterns along the acromion and scapular spine [30]. Clinically, preserving the coracoacromial ligament was associated with a significant reduction of acromial stress reactions and occult fractures following RTSA in a study involving 265 patients [66]. Therefore, maintaining the coracoacromial ligament integrity may be a modifiable risk factor for acromial fractures following RTSA.

The location of the acromion or scapular spine fracture not only influences patient outcome, but also plays an important role in the choice of treatment $[17,18,22]$. Based on the Levy classification [20], type II fractures are most common (50\%), followed by type III $(38 \%)$, and type I fractures (12\%). The four biomechanical studies that analysed the influence of the Levy zones on acromial and scapular spine strain [14,46-48] confirmed this finding by observing the highest stress and strain values in zone II and III, respectively. In the study by Zeng et al. [48], strain was highest in zone II. Wong et al. [47] also located the highest stress in Levy zone II, followed by zone III and zone I. Similarly, Kerrigan et al. [46] measured highest strain in zone II. In a study by Lockhart et al. [14], the stress in zone II was the greatest regardless of implant configuration, loads, and plane of elevation, followed by zone III and zone I.

The Levy zones also play a relevant role in the treatment of acromial and scapular spine fractures. Type I and some type II fractures can be treated non-operatively [24], with a moderate union rate of about $50 \%$ and an acceptable functional outcome [17,22]. Type III fractures are challenging to treat as the broad deltoid muscle insertion and poor fragment bone stock compromise stable fixation $[15,20,25,26]$. Although open reduction and internal fixation is the preferred treatment method, it is associated with a high nonunion rate $[16,22,67,68]$. Similarly, non-operative management with an abduction splint is also associated with a high non-union rate and does not reveal superior results over surgical fixation $[16,22]$. The resulting tilt of the most lateral scapular fragment leads to impingement, reduced range of motion, and ongoing pain [23]. Therefore, acromial and scapular spine fractures after RTSA are not only a common problem but also hard to treat $[15,17,24,69,70]$.

There are several limitations to this study. Firstly, PROSPERO registration was conducted after completion of this systematic review. However, the study protocol was strictly followed and has not been changed during the conduction of this study nor before submission to PROSPERO. Secondly, the included studies reported on varying implant factors that could affect stress on the acromion. In all, there was limited data to allow meta-analysis. Nonetheless, a comprehensive description of data and comparison were possible to derive a meaningful discussion. Thirdly, the studies involved were either computational analyses or cadaveric studies. These have inherent limitations in replicating results in in-vivo biomechanics and physiology. However, these studies were conducted with consistent design and testing protocols in the exclusion of other potential interfering variables, such as the rotator cuff. This provides accurate results on true strain/stress response at the acromion 
and scapular spine resulting from altered deltoid forces. Fourthly, the base implant models were varied with differing NSA between studies. The impact of this in interpreting and comparing results is uncertain. Finally, acromial and scapular spine fractures are the result of bony stress of a certain cross-sectional area exceeding the bony strength in this area. Although this study discussed factors influencing bony stress, it did not consider bony acromial and scapular spine strength. Risk factors such as osteoporosis, cuff tear arthropathy, inflammatory arthritis, or older age are known to be associated with acromial and scapular spine fractures following RTSA [71]. When planning RTSA, both factors altering bony stress as well as factors affecting bone strength need to be considered and this combination of factors should be studied in future.

\section{Conclusions}

Glenoid lateralization was consistently associated with increased acromial and scapular spine strain, whereas inferiorization of the glenosphere reduced strain in the biomechanical studies analysed in this systematic review. Humeral-sided lateralization may increase or decrease acromial or scapular spine strain. Independent of different design parameters, transection of the coracoacromial ligament resulted in significantly increased strains, and scapular spine strains were also increased when the acromion was more posteriorly oriented. The results found in this systematic review of biomechanical in-silico and in-vitro studies may help in surgical planning of RTSA to mitigate complications associated with acromion and scapular spine fractures.

Supplementary Materials: The following are available online at https://www.mdpi.com/article/10 .3390/jcm11020361/s1, File S1: PRISMA_2020_checklist, File S2: PROSPERO public record, File S3: search strategy.

Author Contributions: Conceptualization, L.E.; methodology, L.E.; software, A.P. and O.J.; validation, N/A; formal analysis, A.P. and O.J.; investigation, A.P. and O.J.; resources, N/A; data curation, A.P., O.J. and L.E.; writing—original draft preparation, A.P., O.J. and L.E.; writing—review and editing, A.P., O.J., H.S.R., D.C.A., T.T., C.P., G.H., E.T.E. and L.E.; visualization, H.S.R. and L.E.; supervision, L.E.; project administration, L.E.; funding acquisition, N/A. All authors have read and agreed to the published version of the manuscript.

Funding: This research received no external funding.

Conflicts of Interest: The authors declare no conflict of interest related to this study.

\section{References}

1. Drake, G.N.; O'Connor, D.P.; Edwards, T.B. Indications for reverse total shoulder arthroplasty in rotator cuff disease. Clin. Orthop. Relat. Res. 2010, 468, 1526-1533. [CrossRef]

2. Ek, E.T.; Neukom, L.; Catanzaro, S.; Gerber, C. Reverse total shoulder arthroplasty for massive irreparable rotator cuff tears in patients younger than 65 years old: Results after five to fifteen years. J. Shoulder Elb. Surg. 2013, 22, 1199-1208. [CrossRef]

3. Ernstbrunner, L.; Andronic, O.; Grubhofer, F.; Camenzind, R.S.; Wieser, K.; Gerber, C. Long-term results of reverse total shoulder arthroplasty for rotator cuff dysfunction: A systematic review of longitudinal outcomes. J. Shoulder Elb. Surg. 2019, 28, 774-781. [CrossRef]

4. Ernstbrunner, L.; Suter, A.; Catanzaro, S.; Rahm, S.; Gerber, C. Reverse Total Shoulder Arthroplasty for Massive, Irreparable Rotator Cuff Tears Before the Age of 60 Years: Long-Term Results. J. Bone Jt. Surg. 2017, 99, 1721-1729. [CrossRef] [PubMed]

5. Ernstbrunner, L.; Werthel, J.D.; Wagner, E.; Hatta, T.; Sperling, J.W.; Cofield, R.H. Glenoid bone grafting in primary reverse total shoulder arthroplasty. J. Shoulder Elb. Surg. 2017, 26, 1441-1447. [CrossRef]

6. Gerber, C.; Canonica, S.; Catanzaro, S.; Ernstbrunner, L. Longitudinal observational study of reverse total shoulder arthroplasty for irreparable rotator cuff dysfunction: Results after 15 years. J. Shoulder Elb. Surg. Surg. 2018, 28, 774-781. [CrossRef] [PubMed]

7. Yahuaca, B.I.; Simon, P.; Christmas, K.N.; Patel, S.; Gorman, R.A.; Mighell, M.A.; Frankle, M.A. Acute surgical management of proximal humerus fractures: ORIF vs. hemiarthroplasty vs. reverse shoulder arthroplasty. J. Shoulder Elb. Surg. 2020, 29, S32-S40. [CrossRef]

8. Sabah, Y.; Decroocq, L.; Gauci, M.O.; Bonnevialle, N.; Lemmex, D.B.; Chelli, M.; Valenti, P.; Boileau, P. Clinical and radiological outcomes of reverse shoulder arthroplasty for acute fracture in the elderly. Int. Orthop. 2021, 45, 1775-1781. [CrossRef]

9. Cazeneuve, J.F.; Cristofari, D.J. Delta III reverse shoulder arthroplasty: Radiological outcome for acute complex fractures of the proximal humerus in elderly patients. Orthop. Traumatol. Surg. Res. OTSR 2009, 95, 325-329. [CrossRef] 
10. Ernstbrunner, L.; Rahm, S.; Suter, A.; Imam, M.; Catanzaro, S.; Grubhofer, F.; Gerber, C. Salvage reverse total shoulder arthroplasty for failed operative treatment of proximal humeral fractures in patients younger than 60 years: Long-term results. J. Shoulder Elb. Surg. 2019, 29, 561-570. [CrossRef] [PubMed]

11. Flury, M.P.; Frey, P.; Goldhahn, J.; Schwyzer, H.-K.; Simmen, B.R. Reverse shoulder arthroplasty as a salvage procedure for failed conventional shoulder replacement due to cuff failure-midterm results. Int. Orthop. 2011, 35, 53-60. [CrossRef]

12. Grammont, P.; Trouilloud, P.; Laffay, J.; Deries, X. Etude et réalisation d'une nouvelle prothèse d'épaule. Rhumatologie 1987, 39, 407-418.

13. Boileau, P.; Watkinson, D.J.; Hatzidakis, A.M.; Balg, F. Grammont reverse prosthesis: Design, rationale, and biomechanics. J. Shoulder Elb. Surg. 2005, 14, 147S-161S. [CrossRef]

14. Lockhart, J.S.; Wong, M.T.; Langohr, G.D.G.; Athwal, G.S.; Johnson, J.A. The effect of arm loading and plane of elevation on acromial stress after reverse shoulder arthroplasty. J Orthop. Res 2017, 35, 388-395.

15. Crosby, L.A.; Hamilton, A.; Twiss, T. Scapula fractures after reverse total shoulder arthroplasty: Classification and treatment. Clin. Orthop. Relat. Res. 2011, 469, 2544-2549. [CrossRef] [PubMed]

16. Hamid, N.; Connor, P.M.; Fleischli, J.F.; D'Alessandro, D.F. Acromial fracture after reverse shoulder arthroplasty. Am. J. Orthop. 2011, 40, E125-E129. [PubMed]

17. Hattrup, S.J. The influence of postoperative acromial and scapular spine fractures on the results of reverse shoulder arthroplasty. Orthopedics 2010, 33, 302. [CrossRef]

18. Walch, G.; Mottier, F.; Wall, B.; Boileau, P.; Molé, D.; Favard, L. Acromial insufficiency in reverse shoulder arthroplasties. J. Shoulder Elb. Surg. 2009, 18, 495-502. [CrossRef]

19. Cuff, D.; Pupello, D.; Virani, N.; Levy, J.; Frankle, M. Reverse shoulder arthroplasty for the treatment of rotator cuff deficiency. J. Bone Jt. Surg. Am. 2008, 90, 1244-1251. [CrossRef]

20. Levy, J.C.; Anderson, C.; Samson, A. Classification of postoperative acromial fractures following reverse shoulder arthroplasty. J. Bone Jt. Surg. Am. 2013, 95, e104. [CrossRef]

21. Zhou, H.S.; Chung, J.S.; Yi, P.H.; Li, X.; Price, M.D. Management of complications after reverse shoulder arthroplasty. Curr. Rev. Musculoskelet. Med. 2015, 8, 92-97. [CrossRef]

22. Teusink, M.J.; Otto, R.J.; Cottrell, B.J.; Frankle, M.A. What is the effect of postoperative scapular fracture on outcomes of reverse shoulder arthroplasty? J. Shoulder Elb. Surg. 2014, 23, 782-790. [CrossRef] [PubMed]

23. Neyton, L.; Erickson, J.; Ascione, F.; Bugelli, G.; Lunini, E.; Walch, G. Grammont Award 2018: Scapular fractures in reverse shoulder arthroplasty (Grammont style): Prevalence, functional, and radiographic results with minimum 5-year follow-up. J. Shoulder Elb. Surg. 2019, 28, 260-267. [CrossRef]

24. Mayne, I.P.; Bell, S.N.; Wright, W.; Coghlan, J.A. Acromial and scapular spine fractures after reverse total shoulder arthroplasty. Shoulder Elb. 2016, 8, 90-100. [CrossRef] [PubMed]

25. Patterson, D.C.; Chi, D.; Parsons, B.O.; Cagle, P.J. Acromial spine fracture after reverse total shoulder arthroplasty: A systematic review. J. Shoulder Elb. Surg. 2019, 28, 792-801. [CrossRef] [PubMed]

26. Frankle, M.; Siegal, S.; Pupello, D.; Saleem, A.; Mighell, M.; Vasey, M. The Reverse Shoulder Prosthesis for glenohumeral arthritis associated with severe rotator cuff deficiency. A minimum two-year follow-up study of sixty patients. J. Bone Jt. Surg. Am. Vol. 2005, 87, 1697-1705. [CrossRef]

27. Farshad, M.; Gerber, C. Reverse total shoulder arthroplasty-from the most to the least common complication. Int. Orthop. 2010, 34, 1075-1082. [CrossRef] [PubMed]

28. Moverman, M.A.; Menendez, M.E.; Mahendraraj, K.A.; Polisetty, T.; Jawa, A.; Levy, J.C. Patient risk factors for acromial stress fractures after reverse shoulder arthroplasty: A multicenter study. J. Shoulder Elb. Surg. 2021, 30, 1619-1625. [CrossRef] [PubMed]

29. Shah, S.S.; Gentile, J.; Chen, X.; Kontaxis, A.; Dines, D.M.; Warren, R.F.; Taylor, S.A.; Jahandar, A.; Gulotta, L.V. Influence of implant design and parasagittal acromial morphology on acromial and scapular spine strain after reverse total shoulder arthroplasty: A cadaveric and computer-based biomechanical analysis. J. Shoulder Elb. Surg. 2020, 29, 2395-2405. [CrossRef]

30. Taylor, S.A.; Shah, S.S.; Chen, X.; Gentile, J.; Gulotta, L.V.; Dines, J.S.; Dines, D.M.; Cordasco, F.A.; Warren, R.F.; Kontaxis, A. Scapular Ring Preservation: Coracoacromial Ligament Transection Increases Scapular Spine Strains Following Reverse Total Shoulder Arthroplasty. J. Bone Jt. Surg. 2020, 102, 1358-1364. [CrossRef] [PubMed]

31. Giles, J.W.; Langohr, G.D.; Johnson, J.A.; Athwal, G.S. Implant Design Variations in Reverse Total Shoulder Arthroplasty Influence the Required Deltoid Force and Resultant Joint Load. Clin. Orthop. Relat. Res. 2015, 473, 3615-3626. [CrossRef]

32. Henninger, H.B.; Barg, A.; Anderson, A.E.; Bachus, K.N.; Burks, R.T.; Tashjian, R.Z. Effect of lateral offset center of rotation in reverse total shoulder arthroplasty: A biomechanical study. J. Shoulder Elb. Surg. 2012, 21, 1128-1135. [CrossRef]

33. Schenk, P.; Aichmair, A.; Beeler, S.; Ernstbrunner, L.; Meyer, D.C.; Gerber, C. Acromial Fractures Following Reverse Total Shoulder Arthroplasty: A Cohort Controlled Analysis. Orthopedics 2020, 43, 15-22. [CrossRef] [PubMed]

34. Werthel, J.D.; Schoch, B.S.; van Veen, S.C.; Elhassan, B.T.; An, K.N.; Cofield, R.H.; Sperling, J.W. Acromial Fractures in Reverse Shoulder Arthroplasty: A Clinical and Radiographic Analysis. J. Shoulder Elb. Arthroplast. 2018, 2, 2471549218777628. [CrossRef]

35. Page, M.J.; McKenzie, J.E.; Bossuyt, P.M.; Boutron, I.; Hoffmann, T.C.; Mulrow, C.D.; Shamseer, L.; Tetzlaff, J.M.; Akl, E.A.; Brennan, S.E.; et al. The PRISMA 2020 statement: An updated guideline for reporting systematic reviews. BMJ 2021, 372, n71. [CrossRef] 
36. Werner, B.S.; Ascione, F.; Bugelli, G.; Walch, G. Does arm lengthening affect the functional outcome in onlay reverse shoulder arthroplasty? J. Shoulder Elb. Surg. 2017, 26, 2152-2157. [CrossRef] [PubMed]

37. Hodgson, S. AO principles of fracture management. Ann. R. Coll. Surg. Engl. 2009, 91, 448-449. [CrossRef]

38. Downs, S.H.; Black, N. The feasibility of creating a checklist for the assessment of the methodological quality both of randomised and non-randomised studies of health care interventions. J. Epidemiol. Community Health 1998, 52, 377-384. [CrossRef] [PubMed]

39. Hik, F.; Ackland, D.C. The moment arms of the muscles spanning the glenohumeral joint: A systematic review. J. Anat. 2019, 234, 1-15. [CrossRef]

40. Hansen, M.; Nayak, A.; Sathia, M.; Worhacz, K.; Stowell, R.; Jacofsky, M.; Roche, C. The impact of a novel proximal humerus muscle augment on deltoid and posterior rotator cuff force requirements and the overall joint reaction force with reverse total shoulder arthroplasty. J. Orthop. Res. 2016, 34, S1.

41. Lewicki, K.A.; Bell, J.E.; Van Citters, D.W. The influence of reverse shoulder lateralization on deltoid activation and scapular fracture: A modeling study. J. Orthop. Res. 2017, 35.

42. Onstot, B.R.; Jacofsky, M.C.; Hansen, M.L. Muscle force and excursion requirements and moment arm analysis of a posteriorsuperior offset reverse total shoulder prosthesis. Bull. Hosp. Jt. Dis. 2013, 71, S25-S30.

43. Ott, N.; Alikah, A.; Hackl, M.; Seybold, D.; Müller, L.P.; Wegmann, K. The effect of glenoid lateralization and glenosphere size in reverse shoulder arthroplasty on deltoid load: A biomechanical cadaveric study. J. Orthop. 2021, 25, 107-111. [CrossRef]

44. Humphrey, C.S.; Kelly Ii, J.D.; Norris, T.R. Optimizing glenosphere position and fixation in reverse shoulder arthroplasty, Part Two: The three-column concept. J. Shoulder Elb. Surg. 2008, 17, 595-601. [CrossRef]

45. Wright, M.A.; Murthi, A.M. Offset in Reverse Shoulder Arthroplasty: Where, When, and How Much. J. Am. Acad. Orthop. Surg. 2021, 29, 89-99. [CrossRef]

46. Kerrigan, A.M.; Reeves, J.M.; Langohr, G.D.G.; Johnson, J.A.; Athwal, G.S. The influence of reverse arthroplasty humeral component design features on scapular spine strain. J. Shoulder Elb. Surg. 2021, 30, 572-579. [CrossRef] [PubMed]

47. Wong, M.T.; Daniel, G.; Langohr, G.; Athwal, G.S.; Johnson, J.A. Implant positioning has an effect on acromial stresses in reverse shoulder arthroplasty. J. Orthop. Res. 2016, 34, 1889-1895.

48. Zeng, W.; Lewicki, K.A.; Chen, Z.; Van Citters, D.W. The evaluation of reverse shoulder lateralization on deltoid forces and scapular fracture risk: A computational study. Med. Nov. Technol. Devices 2021, 11, 100076. [CrossRef]

49. Wong, M.T.; Langohr, G.D.G.; Athwal, G.S.; Johnson, J.A. Implant positioning in reverse shoulder arthroplasty has an impact on acromial stresses. J. Shoulder Elb. Surg. 2016, 25, 1889-1895. [CrossRef] [PubMed]

50. Franceschetti, E.; de Sanctis, E.G.; Ranieri, R.; Palumbo, A.; Paciotti, M.; Franceschi, F. The role of the subscapularis tendon in a lateralized reverse total shoulder arthroplasty: Repair versus nonrepair. Int. Orthop. 2019, 43, 2579-2586. [CrossRef]

51. Costantini, O.; Choi, D.S.; Kontaxis, A.; Gulotta, L.V. The effects of progressive lateralization of the joint center of rotation of reverse total shoulder implants. J. Shoulder Elb. Surg. 2015, 24, 1120-1128. [CrossRef]

52. Langohr, G.D.; Giles, J.W.; Athwal, G.S.; Johnson, J.A. The effect of glenosphere diameter in reverse shoulder arthroplasty on muscle force, joint load, and range of motion. J. Shoulder Elb. Surg. 2015, 24, 972-979. [CrossRef]

53. Routman, H.D.; Flurin, P.H.; Wright, T.W.; Zuckerman, J.D.; Hamilton, M.A.; Roche, C.P. Reverse Shoulder Arthroplasty Prosthesis Design Classification System. Bull. Hosp. Jt. Dis. 2015, 73, S5-S14.

54. Roche, C.P.; Diep, P.; Hamilton, M.; Crosby, L.A.; Flurin, P.H.; Wright, T.W.; Zuckerman, J.D.; Routman, H.D. Impact of inferior glenoid tilt, humeral retroversion, bone grafting, and design parameters on muscle length and deltoid wrapping in reverse shoulder arthroplasty. Bull. Hosp. Jt. Dis. 2013, 71, 284-293.

55. Hoenecke, H.R.; Flores-Hernandez, C.; D'Lima, D.D. Reverse total shoulder arthroplasty component center of rotation affects muscle function. J. Shoulder Elb. Surg. 2014, 23, 1128-1135. [CrossRef]

56. Nolte, P.C.; Miles, J.W.; Tanghe, K.K.; Brady, A.W.; Midtgaard, K.S.; Cooper, J.D.; Lacheta, L.; Provencher, M.T.; Millett, P.J. The effect of glenosphere lateralization and inferiorization on deltoid force in reverse total shoulder arthroplasty. J. Shoulder Elb. Surg. 2021, 30, 1817-1826. [CrossRef] [PubMed]

57. Oh, J.H.; Shin, S.J.; McGarry, M.H.; Scott, J.H.; Heckmann, N.; Lee, T.Q. Biomechanical effects of humeral neck-shaft angle and subscapularis integrity in reverse total shoulder arthroplasty. J. Shoulder Elb. Surg. 2014, 23, 1091-1098. [CrossRef] [PubMed]

58. Helmkamp, J.K.; Bullock, G.S.; Amilo, N.R.; Guerrero, E.M.; Ledbetter, L.S.; Sell, T.C.; Garrigues, G.E. The clinical and radiographic impact of center of rotation lateralization in reverse shoulder arthroplasty: A systematic review. J. Shoulder Elb. Surg. 2018, 27, 2099-2107. [CrossRef] [PubMed]

59. Gorman, R.A.; Christmas, K.N.; Simon, P.; Mighell, M.A.; Frankle, M.A. A cohort comparison of humeral implant designs in reverse shoulder arthroplasty: Does implant design lead to lower rates of complications and revision? J. Shoulder Elb. Surg. 2021, 30, 850-857. [CrossRef] [PubMed]

60. Ladermann, A.; Denard, P.J.; Boileau, P.; Farron, A.; Deransart, P.; Terrier, A.; Ston, J.; Walch, G. Effect of humeral stem design on humeral position and range of motion in reverse shoulder arthroplasty. Int. Orthop. 2015, 39, 2205-2213. [CrossRef] [PubMed]

61. Nelson, R.; Lowe, J.T.; Lawler, S.M.; Fitzgerald, M.; Mantell, M.T.; Jawa, A. Lateralized center of rotation and lower neck-shaft angle are associated with lower rates of scapular notching and heterotopic ossification and improved pain for reverse shoulder arthroplasty at 1 year. Orthopedics 2018, 41, 230-236. [CrossRef]

62. Hamilton, M.A.; Roche, C.P.; Diep, P.; Flurin, P.H.; Routman, H.D. Effect of prosthesis design on muscle length and moment arms in reverse total shoulder arthroplasty. Bull. Hosp. Jt. Dis. 2013, 71, S31-S35. 
63. Reintgen, C.; Armington, S.; Vigan, M.; Werthel, J.D.; Patrick, M.; King, J.; Wright, T.; Schoch, B. Influence of Thoracic Kyphosis on Reverse Total Shoulder Arthroplasty Outcomes. J. Am. Acad. Orthop. Surg. 2021, 29, 840-847. [CrossRef]

64. Putz, R.; Liebermann, J.; Reichelt, A. The function of the coracoacromial ligament. Acta Anat. 1988, 131, 140-145. [CrossRef] [PubMed]

65. Gallino, M.; Battiston, B.; Annaratone, G.; Terragnoli, F. Coracoacromial ligament: A comparative arthroscopic and anatomic study. Arthroscopy 1995, 11, 564-567. [CrossRef]

66. Baek Md, C.H.; Kim Md, J.G.; Lee Md, D.H.; Baek, G.R. Does Preservation of Coracoacromial Ligament Reduce the Acromial Stress Pathology Following Reverse Total Shoulder Arthroplasty? J. Shoulder Elb. Arthroplast. 2021, 5, 24715492211022171. [CrossRef] [PubMed]

67. Lópiz, Y.; Rodríguez-González, A.; García-Fernández, C.; Marco, F. Scapula insufficiency fractures after reverse total shoulder arthroplasty in rotator cuff arthropathy: What is their functional impact? Rev. Esp. Cir. Ortop. Traumatol. 2015, 59, 318-325. [CrossRef]

68. Stevens, C.G.; Murphy, M.R.; Stevens, T.D.; Bryant, T.L.; Wright, T.W. Bilateral scapular fractures after reverse shoulder arthroplasties. J. Shoulder Elb. Surg. 2015, 24, e50-e55. [CrossRef]

69. Wahlquist, T.C.; Hunt, A.F.; Braman, J.P. Acromial base fractures after reverse total shoulder arthroplasty: Report of five cases. J. Shoulder Elb. Surg. 2011, 20, 1178-1183. [CrossRef]

70. Rouleau, D.M.; Gaudelli, C. Successful treatment of fractures of the base of the acromion after reverse shoulder arthroplasty: Case report and review of the literature. Int. J. Shoulder Surg. 2013, 7, 149-152. [CrossRef]

71. Group, A.C.o.R.R.; Mahendraraj, K.A.; Abboud, J.; Armstrong, A.; Austin, L.; Brolin, T.; Entezari, V.; Friedman, L.; Garrigues, G.E.; Grawe, B.; et al. Predictors of acromial and scapular stress fracture after reverse shoulder arthroplasty: A study by the ASES Complications of RSA Multicenter Research Group. J. Shoulder Elb. Surg. 2021, 30, 2296-2305. [CrossRef] 